\title{
Prevalence and predictors of cannabis use among men receiving androgen-deprivation therapy for advanced prostate cancer
}

\author{
Ahmad Mousa, MD ${ }^{1,2}$; Michele Petrovic, $\mathrm{BSc}^{2}$; Neil E. Fleshner, MD, MPH, FRCSC ${ }^{1,2}$ \\ ${ }^{1}$ University of Toronto, Faculty of Medicine, Toronto, ON, Canada; ${ }^{2}$ Division of Urology, Department of Surgery, \\ University of Toronto, Toronto, ON, Canada
}

Cite as: Can Urol Assoc J 2019 June 17; Epub ahead of print. http://dx.doi.org/10.5489/cuaj.5911

Published online June 17, 2019

$* * *$

\begin{abstract}
Introduction: Prostate cancer patients receiving androgen-deprivation therapy (ADT) often experience a combination of disease symptoms and treatment side effects. The therapeutic use of cannabis to alleviate these side effects has not been studied, despite increasing patient interest. With the increasing availability of cannabis, it is important for clinicians to understand the prevalence, predictors, and perceived benefits of cannabis use among patients with prostate cancer.
\end{abstract}

Methods: A total of 222 men undergoing ADT were assessed in this two-part study. In part one, the cannabis-use questionnaire was administered to 56 men, probing demographics, usage habits, perspectives, and degrees of symptom relief related to cannabis use. In part two, 191 cryopreserved urine samples were retrieved and analyzed for the presence of tetrahydrocannabidiol (THC) metabolite 11-nor- $\Delta$ 9-THC-COOH. The respondents were then stratified into two groups, users vs. non-users, and statistical analyses were conducted.

Results: Questionnaire data revealed that $23.2 \%$ of surveyed men had recently used cannabis. In contrast, $5.8 \%$ of men had detectable levels of THC metabolite in their urine. Combined questionnaire and urine data revealed that cannabis users were significantly younger $(p=0.003)$ and had lower testosterone levels $(\mathrm{p}=0.003)$ than non-users. The majority of men experiencing common ADT side effects reported some degree of relief following cannabis use.

Conclusions: Cannabis use among men with advanced prostate cancer receiving ADT is more prevalent than in the general population and the majority of other oncological cohorts. Lower testosterone levels and reported therapeutic benefit among cannabis users warrants confirmation in appropriate clinical trials. 


\section{Introduction}

Cannabis use by humans has been documented since ancient history. Despite its classification as a controlled substance in many countries, cannabis (most commonly Cannabis sativa) has recently made strides towards decriminalization and acceptance by mainstream society. In 2001, cannabis was legalized for medical use in Canada following recommendations by Health Canada. A United Nations study estimated that $12.6 \%$ of Canadian adults have used cannabis in the past year, which is a remarkably higher rate than the global average of $2.8-4.5 \%{ }^{1}$. Of particular interest, the use of cannabis has increased by over $1.5 \%$ in adults aged 45 or older since $2002{ }^{2}$. Recent international moves towards decriminalization of cannabis have resulted in an increase in public interest for both its recreational and medical uses. Physician interest and approval for cannabis use has been well documented in several studies, most recently in 2013, when a poll of 1446 physicians revealed that $76 \%$ approved of medical marijuana use ${ }^{3}$.

Several studies have shown that $C$. sativa exhibits some efficacy in relieving nausea and vomiting ${ }^{4}$, loss of appetite ${ }^{5}$, and neuropathic pain ${ }^{6}$. The use of cannabis has also been associated with several non-serious adverse events. One study has found that males who have ever smoked cannabis or those who were current cannabis smokers had a higher risk of prostate cancer than those with no history of its use ${ }^{7}$. Reported acute adverse effects of cannabis include impaired episodic memory and learning ${ }^{8}$, anxiety and panic attacks, perceptual alterations, and acute psychomotor retardation ${ }^{9}$. Chronic adverse effects include addiction, chronic bronchitis, and carcinogenicity (if inhaled).

Prostate cancer patients receiving androgen deprivation therapy (ADT) often experience a combination of disease symptoms and treatment side effects, including pain, fatigue, insomnia, hot flushes, irritability, depression, headache, nausea, and vomiting ${ }^{10}$. To our knowledge, there are no published peer-reviewed studies to date which evaluate the prevalence of and/or attitudes of prostate cancer patients towards cannabis use. With the increasing availability and prevalence of cannabis use in the general population, particularly within the age groups experiencing the greatest burden of this disease, it is important that clinicians understand how many of their patients use cannabis and what their attitudes are towards this substance. Our study makes a novel contribution to the literature by evaluating the prevalence and predictors of cannabis use, patients' usage habits, perceived benefits, and opinions on cannabis in patients with advanced prostate cancer. These findings will allow clinicians to better understand the large population of prostate cancer patients which they are serving.

\section{Methods}

This was a two-part study involving 222 men with histologically confirmed invasive prostate cancer receiving ADT at the time of the study. Patient health information, including demographics, disease history, and laboratory values were extracted from medical records and stored separately from other collected data. Blood samples for testosterone levels were collected and analyzed according to institutional guidelines at the University Health Network, Toronto 
Canada. Samples were analyzed using an Abbott Architect i2000 immunoassay, with a functional sensitivity allowing for titres to be reported as low as $0.2 \mathrm{nmol} / \mathrm{L}$. Participants with testosterone levels analyzed at external labs were not included in this study.

In part one of the study, a 5-page questionnaire was developed consisting of 18 multiplechoice questions probing the demographics $(\mathrm{n}=6)$, cannabis usage habits and perspectives $(\mathrm{n}=11)$, and degrees of symptom relief related to cannabis use $(\mathrm{n}=1)$. The questionnaire was approved by the institutional research ethics board at the University Health Network (UHN) in Toronto, Canada. The questionnaire has obvious content validity (Appendix 1). The questionnaire was administered to 56 men with histologically confirmed invasive prostate cancer currently receiving ADT in the outpatient clinic setting at Princess Margaret Cancer Centre in Toronto, Canada. Consent was obtained from patients in clinic and the questionnaire was completed using pen and paper on the same clinic day with research staff available to aid in completion. The questionnaire took approximately 20 minutes to complete. Data were gathered from patients between June and September of 2017. No payment was provided to study participants for their participation. Participants were assigned a study specific numeric identifier and the collected data was de-identified and entered into a password-protected database.

In part two of the study, 191 cryopreserved urine supernatant samples were obtained from the Genitourinary (GU) BioBank at the University Health Network, Toronto, Canada. The GU BioBank is a research ethics board-approved investigator-initiated biobanking program that collects and archives biological specimens and data obtained from consenting urologic oncology patients. Patients providing consent to participate in the GU BioBank had urine specimens procured after the initiation of ADT for hormone sensitive disease. Please note the cryopreserved urine specimens were not necessarily from the same sample of survey respondents, overlap was moderate $(\mathrm{n}=25)$. The samples were subject to a single freeze-thaw cycle and analyzed at the Toxicology Laboratory at The Hospital for Sick Children, Toronto, Canada. Samples were analyzed using an Abbott Architect ci4100 immunoassay (Abbott, Illinois, USA), as per manufacturer's instructions. This analysis detects the presence of the tetrahydrocannabinol (THC) metabolite 11-nor-delta-9-tetrahydrocannabinol (11-nor- $\triangle$ 9-THC-COOH). A positive result indicates the presence of the metabolite at a concentration greater than $50 \mathrm{ng} / \mathrm{mL}$, in concordance with cannabis testing guidelines established by the National Institute on Drug Abuse (NIDA), Department of Health and Human Services (DHHS), and the Substance Abuse and Mental Health Service Agency (SAMSHA).

\section{Statistical analysis}

The respondents were then stratified into two groups, users vs. non-users, and statistical analyses were conducted. For comparisons where combined questionnaire and urine data were analyzed, overlapping participants were stratified according to their self-reported questionnaire responses given the limited sensitivity of the urine assay, as outlined in our Discussion. The data were analyzed using IBM SPSS Statistics version 25 (IVM Corp, Armonk, NY). Missing values 
analysis revealed that no questionnaires had missing responses. Lilliefors tests were conducted to establish normality of the data. Continuous data were analyzed using Student $t$ and MannWhitney $U$ tests. Categorical data were analyzed using Pearson Chi-Square tests.

\section{Results}

\section{Subject characteristics}

There were a total of 56 survey respondents. Approximately $2 \%$ of approached patients declined to participate. Demographics are described in Table 1 . Approximately $75 \%$ of the patients were 61 years of age or older (range between 51 and 93 years). The mean age of survey respondents was 70 years. Although the survey population represented over nine ethnicities, about half of the patients were ethnically European (57\%). Approximately a quarter of the survey respondents had education less than post-secondary education (27\%).

Cryopreserved urine samples were analyzed from a total of 191 patients. Approximately $79 \%$ of the patients were 61 years of age or older (range between 50 and 94). The mean age of patients at the time of urine sample collection was 70. No other demographic data were collected from patients providing urine samples.

\section{Primary outcome}

Questionnaire data revealed that 23.2\% (13/56) of surveyed men undergoing ADT had used cannabis within the past 6 months. In contrast, 5.8\% (11/191) of analyzed urine samples tested positive for the presence of THC metabolite.

\section{Secondary outcomes}

Combined questionnaire and urine data (Table 3) revealed that cannabis users $(n=22)$ tend to be significantly younger (mean age 64.36 vs. 71.48 years; $\mathrm{p}=0.003$ ) and have lower testosterone levels (mean T level 0.48 vs. $0.85 \mathrm{nmol} / \mathrm{L}$; $\mathrm{p}=0.003$ ) compared to non-users $(\mathrm{n}=200)$. When controlled for age, analyses also revealed that users were on ADT for significantly less time than non-users (mean time on ADT 2.19 vs. 3.28 years; $\mathrm{p}=0.011$ ).

Questionnaire data revealed that the most widely used method of cannabis consumption was in oils/tinctures (62\%), followed closely by smoking/vaporization (54\%). Patterns and habits of consumption in the surveyed patients are summarized in Table 4. The most common reasons for cannabis use (see Figure 1) were pain (46\%), low energy (46\%), hot flushes (23\%) and irritability/mood (23\%). With the exception of hot flushes, the majority of men reported some degree of relief from all noted ADT side effects following the use of cannabis (see Figure 2). Notably, 31\% (4/13) of users stated that they believed cannabis could be used to directly treat cancer. Approximately 70\% (9/13) of users reported experiencing at least one of the side effects of cannabis use (see Figure 3). The most commonly reported side effects were increased appetite, memory loss, and cough. 
Among non-users, 79\% (34/43) expressed the belief that cannabis has at least one perceived benefit (Table 5). The most commonly perceived benefits of cannabis use among nonusers were relief from pain, depression, and irritability. Among the surveyed non-users, 28\% (12/43) stated that they believed cannabis could be used to directly treat cancer.

The self-reported use of cannabis in prostate cancer patients is greater than the majority of other oncological cohorts (Figure 4).

\section{Discussion}

This two-part study of prostate cancer patients at a large cancer center located in a region with cannabis legalized for medical use found that nearly a quarter of surveyed patients with prostate cancer on ADT reported current or recent cannabis use. In contrast with the survey data, approximately $6 \%$ of urine samples from men meeting the same inclusion criteria were found to contain THC metabolites. This discrepancy can largely be attributed to the limitations of the assay and the pharmacokinetics of THC and non-THC cannabinoid constituents. The assay used in this study detected the presence of THC metabolite 11-nor- $\Delta$ 9-THC-COOH. THC content varies significantly and is not a significant component of a number of prescription and nonrecreational cannabis products, such as the oils and tinctures which were used by a majority of study respondents ${ }^{11,12}$. Furthermore, in respondents utilizing cannabis products containing THC, urine metabolites can become undetectable as early as 7 days following last use. Rate of THC metabolism depends on several factors, including age, metabolism, usage frequency, dosage, and body habitus ${ }^{13}$. The discrepancy between survey and urine data therefore reflects the need for the development of accurate and simple assays that extend the spectrum of readily available cannabis screening tests beyond THC metabolites. Furthermore, this discrepancy highlights the heterogenous, unregulated nature of cannabis products- a significant barrier in the non-controlled study of cannabis use.

A literature search revealed that although there was an abundance of peer-reviewed studies exploring the associations between cannabis use and cancer incidence; there were only a total of 8 studies evaluating the prevalence of cannabis use among oncological cohorts ${ }^{14,15,16,17 \text {, }}$ $18,19,20,21$. When compared to the reported rates in the majority of these other oncological cohorts, the prevalence of cannabis use in prostate cancer patients on ADT is greater. Despite an abundance of data, these comparisons are limited by the fact the majority of studies reporting cannabis usage rates are single-center studies confounded by site-specific legal, cultural, and geographical factors.

One surprising observation from our study is that compared to non-users, cannabis users had significantly lower testosterone levels. Analyses also revealed that when the data was controlled for age, cannabis users were on ADT for a significantly shorter period of time compared to non-users. Given our finding that cannabis users tend to be younger than non-users, it is difficult to hypothesize that poor Leydig cell reserve is the cause of lower testosterone levels. Previous research in men has demonstrated depression of plasma testosterone levels after 
both acute and chronic cannabis use ${ }^{22,23}$. Further research is required to determine if cannabis use can further lower testosterone levels among men on ADT, particularly in light of novel data suggesting that among men on ADT, lower testosterone levels are associated with improved outcomes ${ }^{24,25}$.

The majority of survey respondents denied any current or recent use of cannabis. Interestingly, 79\% of non-users held a belief that cannabis may help treat at least one of the common symptoms and side effect associated with prostate cancer and ADT. These findings demonstrate the interest and optimism of prostate cancer patients towards potential therapeutic uses of cannabis. Interestingly, the same proportion of users (31\%) and non-users (28\%) believed that cannabis may be used to treat their prostate cancer. The notion that cannabis may have a curative role in cancer management is one that is prevalent among many members of the public and is a popular discussion topic on internet forums around the world ${ }^{26,27}$, despite the absence of any clinical trials to support its use in the primary treatment of malignancies. These findings highlight the need for clinicians to seek appropriate education on the topic in order to engage in effective dialogue with their patients.

It is important to note that the majority men in this study who consumed cannabis reported experiencing at least one side effect. The reported effects were short term and included hallucinations, cough, memory loss, and increased appetite. Due to the study design, long-term side effects of cannabis use were not evaluated. There remains a significant gap in the literature on the evaluation of long-term effects of cannabis, the majority of available data is based on in vitro or preclinical studies, severely outdated, or based on inadequately designed trials with small sample sizes.

We acknowledge a number of limitations of our investigation. Our study was conducted at a single centre within a geographical region where cannabis is a controlled substance that is only available for legal use in a narrow spectrum of indications requiring physician prescription, leading to a combined selection/geographical bias. This selection bias may affect generalizability to other populations. Furthermore, we recognize that self-reported data collected via crosssectional study has inherent limitations and biases. Measurement bias (under-reporting of use) is likely due to two factors: social stigma surrounding cannabis and the legal connotations of the access of cannabis products without a prescription.

\section{Conclusions}

Cannabis use among men with advanced prostate cancer receiving ADT is more prevalent than in the general population and the majority of other oncological cohorts. Testosterone levels appear lower among users and warrants further investigation. Both users and non-users appear to be open and optimistic towards the potential therapeutic benefits of cannabis and these effects should be proven in the context of appropriate clinical trials. 


\section{References}

1. Ducatti Flister, L.: The Economic Case for Marijuana Legalization in Canada. Journal of Alternative Perspectives in the Social Sciences 5.1 (2012).

2. Statistics Canada Census, q82-003x; 2012.

3. Adler, J. N. and James A. C.: Medicinal use of marijuana-polling results. $N$ Engl J Med 368.22 (2013): 866-868.

4. Tramèr, M. R., Carroll, D., Campbell F. A., et al.: Cannabinoids for control of chemotherapy induced nausea and vomiting: quantitative systematic review. BMJ 323.7303 (2001): 16.

5. Cann K., Tim C.: Cannabinoids and appetite: food craving and food pleasure. Int Rev Psychiatry 21.2 (2009): 163-171.

6. Palazzo, E., Luongo, L., Novellis, V., et al.: The role of cannabinoid receptors in the descending modulation of pain. Pharmaceuticals (Basel) 3.8 (2010): 2661-2673.

7. Sidney, S., Quesenberry C. P., Friedman, G.D., et al.: Marijuana use and cancer incidence (California, United States). Cancer Causes Control 8.5 (1997): 722-728.

8. Curran, H. V., Brignell, C., Fletcher, S., et al.: Cognitive and subjective dose-response effects of acute oral $\Delta 9$-tetrahydrocannabinol (THC) in infrequent cannabis users. Psychopharmacology (Berl) 164.1 (2002): 61-70.

9. Hall, W. and Nadia S.: Adverse effects of cannabis. Lancet 352.9140 (1998): 1611-1616.

10. Higano, Celestia S. Side effects of androgen deprivation therapy: monitoring and minimizing toxicity. Urology 61.2 (2003): 32-38.

11. Pitts, J. E., P. J. O'Neil, and K. P. Leggo. Survey Variation in the THC Content of Illicitly Imported Cannabis Products-1984-1989. J Pharm Pharmacol 42.12 (1990): 817-820.

12. Fattore, L. and Walter F.: Beyond THC: the new generation of cannabinoid designer drugs. Front Behav Neurosci 5 (2011): 60.

13. Huestis, M. A.: Pharmacokinetics and metabolism of the plant cannabinoids, $\Delta 9$ tetrahydrocannibinol, cannabidiol and cannabinol. Cannabinoids Springer, Berlin, Heidelberg, 2005. 657-690.

14. Pergam, S. A., Woodfield, M. C., Lee, C. M., et al.: Cannabis use among patients at a comprehensive cancer center in a state with legalized medicinal and recreational use. Cancer 123.22 (2017): 4488-4497.

15. Aldington, S., Harwood, M., Cox, B., et al.: Cannabis use and risk of lung cancer: a casecontrol study. Eur Respir J 31.2 (2008): 280-286.

16. Daling, J. R., Doody, D. R., Sun, X., et al.: Association of marijuana use and the incidence of testicular germ cell tumors. Cancer 115.6 (2009): 1215-1223.

17. Zhang, Z. F., Morgenstern, H., Spitz, M. R., et al.: Marijuana use and increased risk of squamous cell carcinoma of the head and neck. Cancer Epidemiol Biomarkers Prev 8.12 (1999): 1071-1078.

18. Aldington, S., Harwood, M., Cox, B., et al.: Cannabis use and cancer of the head and neck: case-control study. Otolaryngol Head Neck Surg 138.3 (2008): 374-380.

19. Berthiller, J., Straif, K., Boniol, M., et al.: Cannabis smoking and risk of lung cancer in men: a pooled analysis of three studies in Maghreb. J Thorac Oncol 3.12 (2008): 13981403. 
20. Thomas, A. A., Wallner, L. P., Quinn, V. P., et al.: Association between cannabis use and the risk of bladder cancer: results from the California Men's Health Study. Urology 85.2 (2015): 388-393.

21. Firth, N. A.: Marijuana use and oral cancer: a review. Oral Oncol 33.6 (1997): 398-401.

22. Kolodny, R. C., Masters, W. H., Kolodner, R. M., et al.: Depression of plasma testosterone levels after chronic intensive marihuana use. N Engl J Med 290.16 (1974): 872-874.

23. Kolodny, R. C., Lessin, P., Toro, G., et al.: Depression of plasma testosterone with acute marihuana administration. The Pharmacology of Marijuana (1976): 217-225.

24. Klotz, L., O’Callaghan, C., Ding, K., et al.: Nadir testosterone within first year of androgen-deprivation therapy (ADT) predicts for time to castration-resistant progression: a secondary analysis of the PR-7 trial of intermittent versus continuous ADT. J Clin Oncol 33.10 (2015): 1151.

25. Klotz, L., Shayegan, B., Guillemette, C., et al.: Testosterone suppression in the treatment of recurrent or metastatic prostate cancer-A Canadian consensus statement. Can Urol Assoc J 12.2 (2018): 30.

26. User, Online.: Friend Is Using Cannabis Oil as Treatment? Cancer Research UK, 3 Feb. 2017, www.cancerresearchuk.org/about-cancer/cancer-chat/thread/friend-is-usingcannabis-oil-as-treatment.

27. User, Online.: Cannabis Oil and Cancer Treatment Suggestion Forum - Steemit. Steemit, 1 May 2016, steemit.com/journey/@ajwalkerart/cannabis-oil-and-cancer-treatmentsuggestion-forum.

\section{Figures and Tables}


Fig. 1. Reasons for cannabis use among survey respondents. The reasons for user were not mutually exclusive responses.

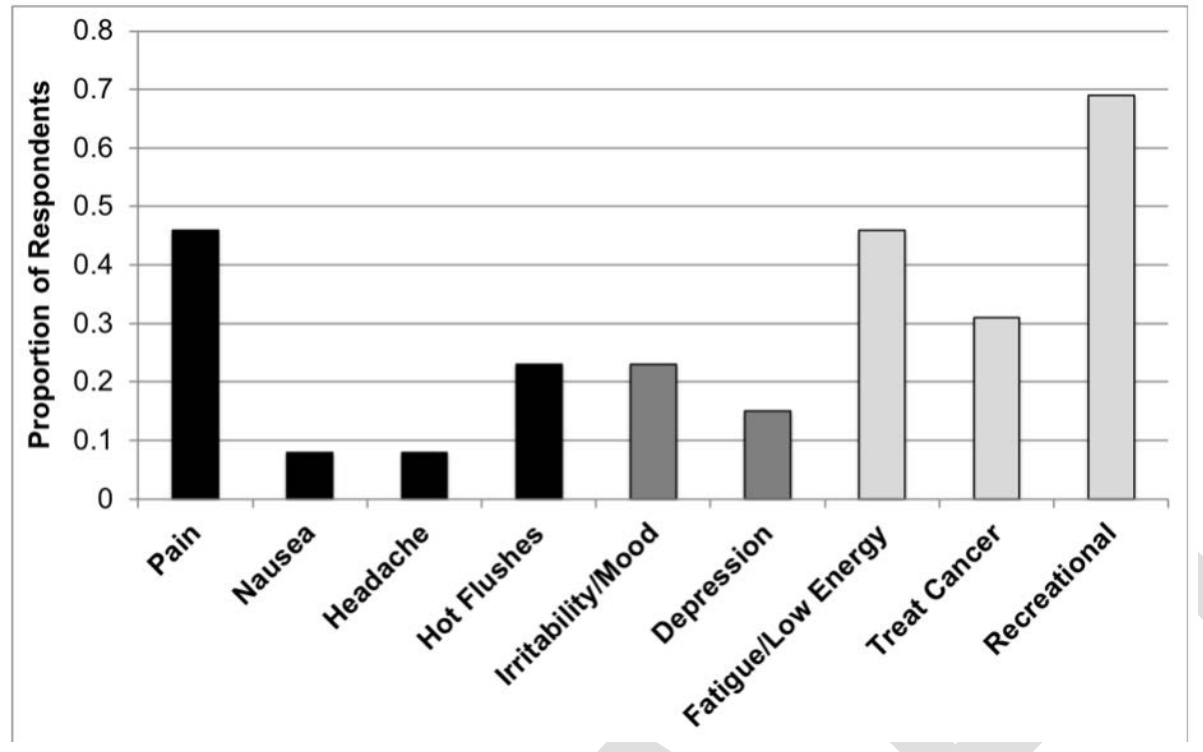

Fig. 2. Reported relied from androgen-deprivation therapy side effects following cannabis use.

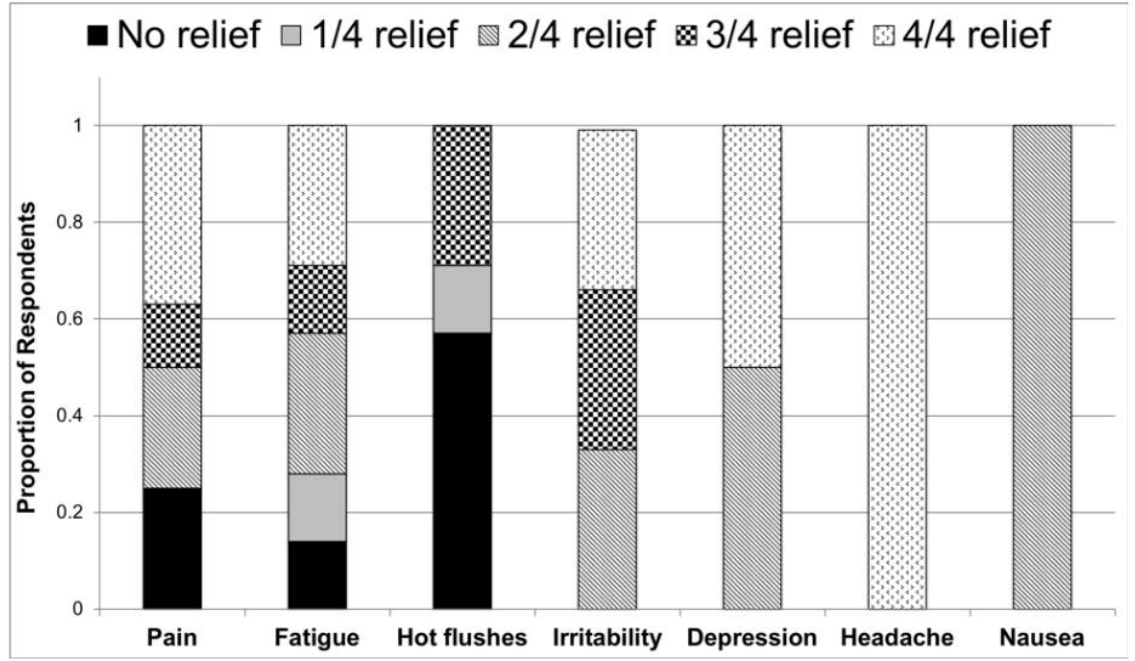


Fig. 3. Reported side effects of cannabis in users. The reported side effects were not mutually exclusive responses.

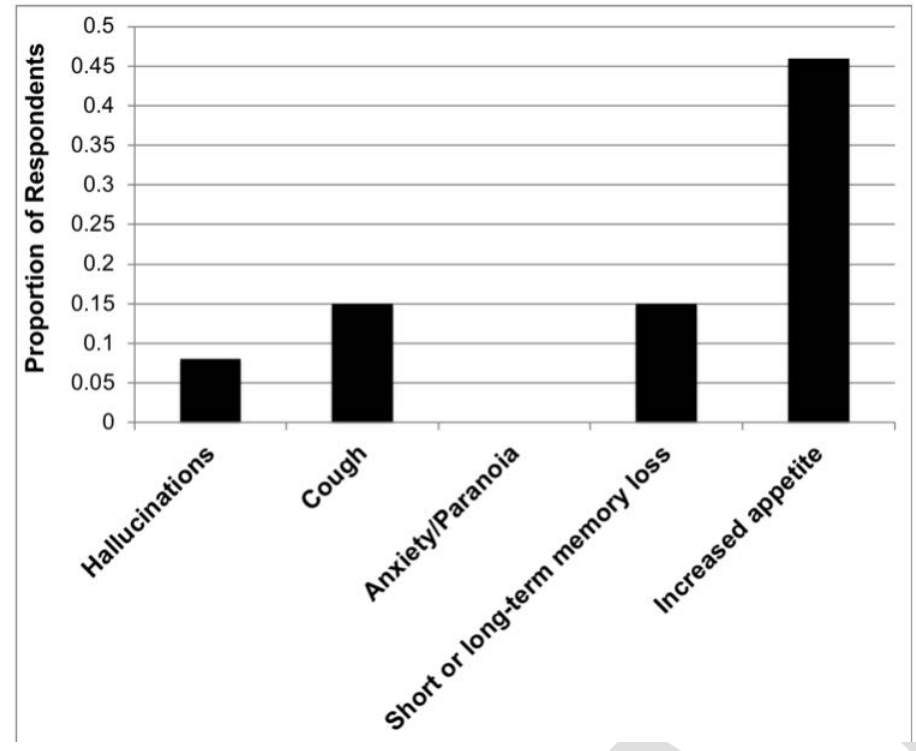

Fig. 4. Self-reported prevalence if cannabis use (\%) among oncological cohorts. GI: gastrointestinal.

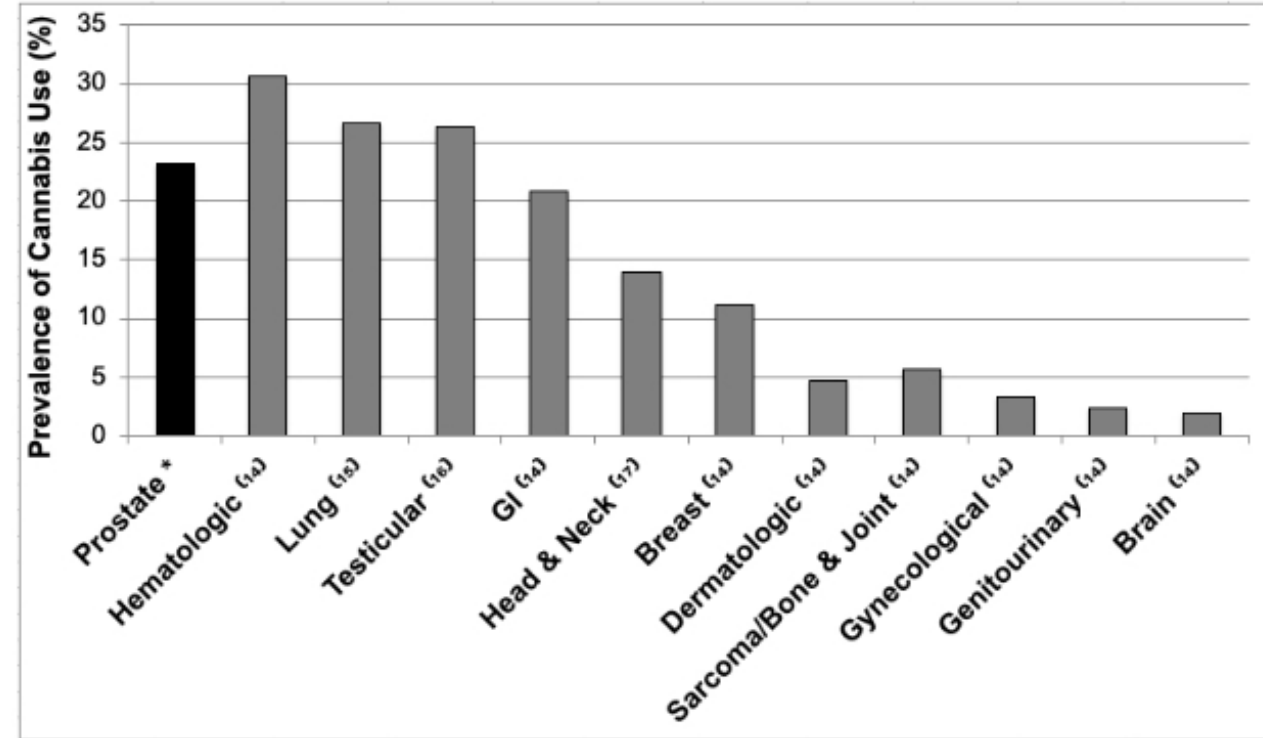




\begin{tabular}{|c|c|c|c|}
\hline Variable & $\begin{array}{c}\text { Non-users } \\
N=43(77 \%) \\
n(\%)\end{array}$ & $\begin{array}{c}\text { Users } \\
\mathrm{N}=13(23 \%) \\
\text { n (\%) }\end{array}$ & $\mathbf{p}$ \\
\hline $\begin{array}{l}\text { Gender } \\
\text { Male }\end{array}$ & $43(100)$ & $13(100)$ & \\
\hline 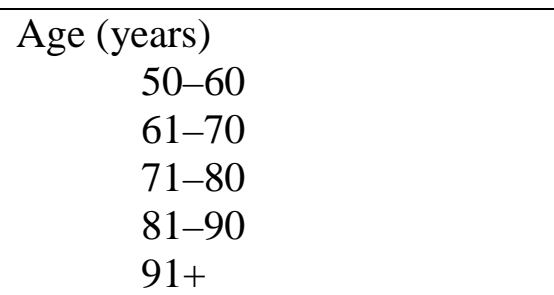 & $\begin{array}{c}8(17) \\
11(26) \\
10(23) \\
12(28) \\
2(5)\end{array}$ & $\begin{array}{l}6(46) \\
3(23) \\
2(15) \\
2(15) \\
0(0)\end{array}$ & \\
\hline $\begin{array}{l}\text { Marital Status } \\
\text { Single } \\
\text { Married } \\
\text { Separated/divorced } \\
\text { Widowed }\end{array}$ & $\begin{array}{c}6(14) \\
30(70) \\
5(12) \\
2(5)\end{array}$ & $\begin{array}{l}3(23) \\
8(62) \\
1(8) \\
1(8)\end{array}$ & 0.817 \\
\hline $\begin{array}{l}\text { Ethnicity } \\
\text { Afro-Caribbean } \\
\text { Arab } \\
\text { Central/South African } \\
\text { East Asian } \\
\text { Eastern European } \\
\text { Indian Subcontinent } \\
\text { Latin } \\
\text { South Pacific/Oceania } \\
\text { Western European } \\
\text { Other }\end{array}$ & $\begin{array}{c}4(9) \\
2(5) \\
1(2) \\
3(7) \\
7(16) \\
3(7) \\
2(5) \\
1(2) \\
16(37) \\
4(9)\end{array}$ & $\begin{array}{c}2(15) \\
1(8) \\
0(0) \\
0(0) \\
4(31) \\
0(0) \\
0(0) \\
0(0) \\
5(38) \\
1(8)\end{array}$ & 0.864 \\
\hline $\begin{array}{l}\text { Education } \\
\text { Less than high school } \\
\text { High school } \\
\text { College } \\
\text { University } \\
\text { Postgraduate }\end{array}$ & $\begin{array}{l}2(5) \\
8(19) \\
12(28) \\
10(23) \\
11(26)\end{array}$ & $\begin{array}{c}2(15) \\
3(23) \\
3(23) \\
4(31) \\
1(8)\end{array}$ & 0.476 \\
\hline $\begin{array}{l}\text { Employment } \\
\text { Full time } \\
\text { Part time } \\
\text { Retired due to disability } \\
\text { Retired due to age } \\
\text { Unemployed }\end{array}$ & $\begin{array}{l}8(19) \\
2(5) \\
5(11) \\
27(63) \\
1(2)\end{array}$ & $\begin{array}{l}7(54) \\
2(15) \\
1(8) \\
3(23) \\
0(0)\end{array}$ & 0.047 \\
\hline
\end{tabular}




\begin{tabular}{|c|c|c|c|}
\hline Annual Income (CAD) & & & 0.866 \\
Less than \$25 000 & $6(14)$ & $1(8)$ & \\
$\$ 25000-\$ 49999$ & $9(21)$ & $2(15)$ & \\
$\$ 50000-\$ 75000$ & $4(9)$ & $4(31)$ \\
More than \$75 000 & $15(35)$ & $4(31)$ & \\
Prefer not to answer & $9(21)$ & \\
\hline
\end{tabular}

\begin{tabular}{|l|c|c|c|}
\hline Table 2A. Characteristics of questionnaire respondents by usage status & \multicolumn{1}{|c|}{ Users } \\
& $\begin{array}{c}\text { Non-users } \\
\text { N=43 (77\%) } \\
\text { Mean (SD) }\end{array}$ & $\begin{array}{c}\text { N=13 (23\%) } \\
\text { Mean (SD) }\end{array}$ & \\
\hline Age (years) & $72(10.63)$ & $65(10.85)$ & $\mathbf{0 . 0 4 3}$ \\
\hline Years on ADT & $3.83(3.61)$ & $1.71(1.50)$ & $\mathbf{0 . 0 2 9}$ \\
Type of ADT & $9(21 \%)$ & $5(38 \%)$ & 0.482 \\
Eligard (Leuprolide) & 0 & 0 & \\
Firmagon (Degarelix) & $17(40 \%)$ & $6(46 \%)$ & \\
Lupron (Leuprolide) & $4(9 \%)$ & 0 & \\
Trelstar (Triptorelin) & $12(28 \%)$ & $2(15 \%)$ & \\
Zoladex (Goserelin) & $1(2 \%)$ & 0 & 0.108 \\
Casodex (Biclutamide) & $1.03(1.68)$ & $0.53(0.51)$ & \\
\hline Most recent testosterone level (nmol/L) & & & \\
& & & \\
\hline
\end{tabular}

ADT: androgen-deprivation therapy; SD: standard deviation.

\begin{tabular}{|l|c|c|c|}
\hline \multicolumn{4}{|c|}{ Table 2B. Characteristics of urine data participants by usage status } \\
\hline & $\begin{array}{c}\text { Non-users } \\
\text { N=180 (94\%) } \\
\text { Mean (SD) }\end{array}$ & $\begin{array}{c}\text { Users } \\
\text { N=11 (6\%) } \\
\text { Mean (SD) }\end{array}$ & p \\
\hline Age (years) & $70.55(10.24)$ & $63.55(8.03)$ & $\mathbf{0 . 0 2 3}$ \\
\hline Years on ADT & $3.00(2.91)$ & $2.59(4.11)$ & $\mathbf{0 . 0 4 6}$ \\
Type of ADT & $27(15 \%)$ & $3(27 \%)$ & 0.856 \\
Eligard (Leuprolide) & $10(6 \%)$ & 0 & \\
Firmagon (Degarelix) & $69(38 \%)$ & $3(27 \%)$ & \\
Lupron (Leuprolide) & $2(1 \%)$ & 0 & \\
Suprefact (Buserelin) & $9(5 \%)$ & $1(9 \%)$ & \\
Trelstar (Triptorelin) & $60(33 \%)$ & $4(36 \%)$ & \\
Zoladex (Goserelin) & $3(2 \%)$ & 0 & \\
Casodex (Biclutamide) & & & \\
\hline
\end{tabular}




\begin{tabular}{|l|c|c|c|}
\hline $\begin{array}{l}\text { Most recent testosterone level } \\
(\mathrm{nmol} / \mathrm{L})\end{array}$ & $0.86(1.34)$ & $0.41(0.24)$ & $\mathbf{0 . 0 1 6}$ \\
\hline
\end{tabular}

ADT: androgen-deprivation therapy; SD: standard deviation.

\begin{tabular}{|c|c|c|c|}
\hline \multicolumn{1}{|c|}{ Table 3. Comparisons of combined questionnaire and urine data by usage status } \\
\hline Variable & $\begin{array}{c}\text { Non-Users } \\
\text { N=200 (90\%) } \\
\text { Mean (SD) }\end{array}$ & $\begin{array}{c}\text { Users } \\
\text { N=22 (10\%) } \\
\text { Mean (SD) }\end{array}$ & p \\
\hline Age (years) & $71.48(10.18)$ & $64.36(9.85)$ & $\mathbf{0 . 0 0 2}$ \\
\hline Years on ADT & $3.28(3.15)$ & $2.19(3.07)$ & $\mathbf{0 . 0 1 0}$ \\
Type of ADT & $28(14 \%)$ & $6(27 \%)$ & 0.626 \\
Eligard (Leuprolide) & $10(5 \%)$ & 0 & \\
Firmagon (Degarelix) & $77(38.5 \%)$ & $9(41 \%)$ & 0 \\
Lupron (Leuprolide) & $2(1 \%)$ & $6(27 \%)$ & \\
Suprefact (Buserelin) & $12(6 \%)$ & 0 & \\
Trelstar (Triptorelin) & $67(33.5 \%)$ & $0.48(0.42)$ & $\mathbf{0 . 0 0 3}$ \\
Zoladex (Goserelin) & $4(2 \%)$ & & \\
\hline $\begin{array}{l}\text { Casodex (Biclutamide) } \\
\text { (nost recent testosterone level }\end{array}$ & $0.85(1.29)$ & & \\
\hline
\end{tabular}

ADT: androgen-deprivation therapy; SD: standard deviation.

Table 4. Patterns of consumption in cannabis users 


\begin{tabular}{|l|c|}
\hline Number of years that subjects have consumed cannabis & $4(31)$ \\
Less than 1 year & $2(15)$ \\
1-3 years & $0(0)$ \\
3-5 years & $7(54)$ \\
Over 5 years & \\
\hline Methods of cannabis consumption & $7(54)$ \\
Smoking/vaporization & $2(15)$ \\
Edibles (smoothies, candies, baked goods, etc.) & $8(62)$ \\
Oils/tinctures & $0(0)$ \\
Topical creams/patches & $0(0)$ \\
Other & $3(23)$ \\
Men utilizing more than one method of consumption & \\
& \\
Number of days per week that cannabis is utilized & $6(46)$ \\
1-2 & $2(15)$ \\
3-4 & $1(8)$ \\
5-6 & $4(31)$ \\
\hline (every day) & \\
Time of use & $1(8)$ \\
Subjects who usually take cannabis just after waking up & $1(8)$ \\
Subjects who usually take cannabis between 6 a.m. and noon & $6(46)$ \\
Subjects who usually take cannabis between noon and 6 p.m. & $4(31)$ \\
Subjects who usually take cannabis just before going to bed & $1(8)$ \\
Subjects who take cannabis whenever it is felt to be necessary & \\
\hline
\end{tabular}

\begin{tabular}{|l|c|}
\hline \multicolumn{2}{|l|}{ Table 5. Opinions on cannabis use in non-users } \\
\hline Do you believe that cannabis may... & n (\%) \\
\hline Treat cancer & $12(28)$ \\
Prevent shrinkage of testicles & $2(5)$ \\
Increase appetite & $10(23)$ \\
Relieve pain & $27(63)$ \\
Relieve fatigue and/or low energy & $12(28)$ \\
Relieve hot flushes & $4(9)$ \\
Relieve irritability and relax mood & $14(33)$ \\
Relieve depression & $15(35)$ \\
Relieve headache & $8(19)$ \\
Relieve nausea & $9(21)$ \\
Relieve vomiting & $5(12)$ \\
Be used for recreation and/or pleasure & $14(33)$ \\
Has no benefits (i.e., responded to no to all) & $9(21)$ \\
\hline
\end{tabular}




\section{CANNABIS OPINION SURVEY}

In order to optimize patient care, our Urology Staff are dedicated towards a better understanding of patient perspectives regarding cannabis use. As a patient currently being treated for prostate cancer, your viewpoints are important to us. In this survey, we will be asking questions regarding your use of cannabis followed by your perspectives and attitudes towards cannabis. Please place an ' $X$ ' in the box next to the best answer to the following questions. All of your responses will be kept confidential.

\section{Correct: $囚 \quad$ Incorrect: $\square(\square$}

1) Marital status:

Single

Married (or committed long term relationship)

Separated/Divorced

Widowed

2) Ethnicity (if mixed decent, select up to 2 predominant ethnicities):

Aboriginal

Afro-Caribbean

Arab

Central Asian (Turkey, Mongolia, Afghanistan...)

$\square$ Central/South African

East African

East Asian (Korea, China, Japan...)

Eastern European

Indian Subcontinent (Sri Lanka, Pakistan, Nepal...)

Latin (South/Central America)

North African

Scandinavian

$\square$ South Pacific/Oceania (Samoa, Fiji, Indonesia...)

Southeast Asian (Vietnam, Thailand)

Southern European

Western European

Other

3) Highest level of education:

Less than high school

High school

College degree or certificate

University undergraduate degree

Post graduate (Master's, PhD, law school, medical school) 
4) Employment:

$\square$ Full time

$\square$ Part time

$\square$ Retired due to disability

$\square$ Retired due to age

$\square$ Unemployed

5) Annual income:

$\square$ Less than $\$ 25,000$

$\square \$ 25,000-\$ 49,999$

$\square \$ 50,000-\$ 75,000$

$\square$ More than $\$ 75,000$

Prefer not to answer

6) Did you require assistance with filling out this survey?

$\square$ Yes

$\square$ No

7) Have you used any cannabis products in the past 6 months?

$\square$ Yes

$\square$ No

IF YOU ANSWERED 'NO' TO QUESTION 7, SKIP TO QUESTION 18 ON PAGE 5 OF SURVEY

IF YOU ANSWERED 'YES' TO QUESTION 7, PLEASE CONTINUE TO QUESTION 8 BELOW

8) Do you currently use any cannabis products?

$\square$ Yes

$\square$ No

9) Please select all the methods of cannabis consumption that you have used:

$\square$ Smoking/vaporization

$\square$ Edibles (smoothies, candies, baked goods, etc.)

$\square$ Oils/tinctures

$\square$ Topical creams/patches

$\square$ Other

10) How many years have you used cannabis?

$\square$ Less than 1 year

$\square$ 1-3 years

$\square$ 3-5 years

$\square$ Over 5 years 
11) How many days per week, on average, do/did you use cannabis?
1-2
3-4
5-6
7 (every day)

12) On days that you use(d) cannabis, how many times, on average did you use per day?

$\square 1-2$

3-4

$\square$ or more

13) What time(s) do you usually use cannabis (please select all that apply)?

$\square$ Just after waking up

$\square$ Between 6 am and noon

$\square$ Between noon and 6pm

Between $6 \mathrm{pm}$ and midnight

$\square$ Just before going bed

Whenever it is/was felt to be necessary

14) Please select all the symptoms that you currently or have previously experienced. If you select a symptom, please specify the degree of relief that you experience(d) after using cannabis by circling a number ranging from 0 (no relief) to 4 (complete relief).

Pain

Please specify (circle) the degree of relief that you experience(d) after using cannabis:

$\begin{array}{ccccc}0 & 1 & 2 & 3 & 4 \\ \text { No relief } & & & & \text { Complete relief }\end{array}$

Fatigue and/or low energy

Please specify (circle) the degree of relief that you experience(d) after using cannabis:

$\begin{array}{ccccc}0 & 1 & 2 & 3 & 4 \\ \text { No relief } & & & & \end{array}$

Hot flashes

Please specify (circle) the degree of relief that you experience(d) after using cannabis:

$\begin{array}{ccccc}0 & 1 & 2 & 3 & 4 \\ \text { No relief } & & & & \text { Complete relief }\end{array}$


Irritability/mood fluctuations

Please specify (circle) the degree of relief that you experience(d) after using cannabis:

$\begin{array}{ccccc}0 & 1 & 2 & 3 & 4 \\ \text { No relief } & & & & \text { Complete relief }\end{array}$

Depression

Please specify (circle) the degree of relief that you experience(d) after using cannabis:

$\begin{array}{cccccc}0 & 1 & 2 & 3 & 4 \\ \text { No relief } & & & & \text { Complete relief }\end{array}$

Headache

Please specify (circle) the degree of relief that you experience(d) after using cannabis:

$\begin{array}{cccccc}0 & 1 & 2 & 3 & 4 \\ \text { No relief } & & & & & \text { Complete relief }\end{array}$

Nausea

Please specify (circle) the degree of relief that you experience(d) after using cannabis:

$\begin{array}{lllll}0 & 1 & 2 & 3 & 4\end{array}$

No relief Complete relief

Vomiting

Please specify (circle) the degree of relief that you experience(d) after using cannabis:

$\begin{array}{lllll}0 & 1 & 2 & 3 & 4\end{array}$

No relief Complete relief

15) I use(d) cannabis to treat my cancer:

True

False

16) I use(d) cannabis recreationally and/or for pleasure:

True

False

17) Please select all the effects that you have experienced during or after the use of cannabis:

$\square$ Hallucinations (of any kind, including auditory, visual, olfactory, gustatory)

Cough

Anxiety/Paranoia

Increased appetite

Short or long-term memory loss 


\section{THE FOLLWING QUESTION (\#18) SHOULD ONLY BE ANSWERED IF YOU HAVE NOT USED CANNABIS IN THE PAST 6 MONTHS}

18) If you have not used cannabis in the past 6 months, please select the symptoms and side effects that you believe cannabis may help with (select all that apply).

$\square$ To treat my cancer

$\square$ Prevent shrinkage of testicles

Increase appetite

Recreational and/or pleasure

Relieve pain

Relieve fatigue and/or low energy

Relieve hot flashes

Relieve irritability/mood relaxation

Relieve depression

Relieve headache

Relieve nausea

Relieve vomiting

Thank you kindly for completing this survey. Results from your answers will provide invaluable insight on patient perspective concerning cannabis use.

\section{END OF SURVEY}

